\title{
POBREZA, CRIMINALIDADE E DIREITOS SOCIAIS: CAUSAS, CONSEQUÊNCIAS E POSSÍVEIS SOLUÇÕES
}

POVERTY, CRIME AND SOCIAL RIGHTS: CAUSES, CONSEQUENCES AND POSSIBLE SOLUTIONS

Denise Oliveira DIAS ${ }^{1}$

ISSUE DOI: $10.21207 / 1983.4225 .499$

\section{RESUMO}

O presente artigo ocupa-se da discussão sobre a pobreza, em como é conceituada; em que compreende e quais suas possíveis afetações. Propõe-se a análise acerca da criminalidade como consequência da pobreza no sentido defendido por teóricos que a apontam como limitação de capacidades e não apenas de recursos materiais. Indica como o Estado poderia atuar como preventor de tal problema social que é a pobreza, a partir da efetividade dos direitos sociais previstos na Constituição Federal de 1988.

Palavras-chave: Pobreza, Direitos, Criminalidade, Efetividade.

\begin{abstract}
This paper deals with the discussion about poverty, how it is conceptualized; what it understands and what its possible affectations are. The analysis of crime as a consequence of poverty is proposed in the sense defended by theorists who point it as a limitation of capacities and not only of material resources. It indicates how the state could act as a preventer of such a social problem that is poverty, based on the effectiveness of the social rights provided for in the Federal Constitution of 1988.
\end{abstract}

Keywords: Poverty, Rights, Crime, Effectiveness.

\footnotetext{
${ }^{1}$ Doutoranda em Ciências Ambientais pela Universidade Federal de Goiás. Mestra em Ambiente e Sociedade pela Universidade Estadual de Goiás. Pós-graduanda em Gestão, Licenciamento e Auditoria Ambiental pela Universidade Anhanguera- Uniderp. Graduada em Direito pela Universidade Salgado de Oliveira. Advogada (OAB 43943). Bolsista CAPES/FAPEG. Contato: denisedias92@gmail.com. http://lattes.cnpq.br/2818861663244195.
} 


\section{INTRODUÇÃO}

O presente trabalho dedica-se à análise das supostas causas da pobreza, suas consequências como a criminalidade e suas possíveis soluções por intermédio da aplicação dos Direitos sociais dispostos na Constituição Federal.

A pobreza é considerada uma carência material ou econômica, portanto em primeiro lugar é feita uma exposição dos pensamentos dos teóricos econômicos Thomas Malthus e Karl Marx sobre as possíveis causas da pobreza nas populações.

Matlhus apontava que a pobreza era um "mal necessário" que atingia às populações por crescerem demasiadamente e assim necessitarem de uma contenção, a qual seria a pobreza, a miséria e as guerras.

Marx dizia que a pobreza era fruto das relações econômicas estabelecidas entre os indivíduos; para o sistema capitalista segundo ele, a pobreza era uma necessidade para que continuasse em vigor.

Em segundo lugar é demonstrada a relação existente entre a pobreza e a criminalidade, tendo em vista que a pobreza não é condição determinante para o crime, mas é uma predisposição. Pois a pobreza gera fatores como a exclusão social que pode ser uma tendência à criminalidade.

Em terceiro lugar, passa-se ao estudo dos Direitos Sociais estabelecidos na Constituição Federal como instrumento de manifestação da justiça segundo John Rawls, que trata da conceituação da justiça como equidade.

O cumprimento dos Direitos Sociais pelo Estado pode ser considerado como propulsor da equidade na sociedade brasileira, contribuindo para a erradicação da pobreza e seus decorrentes fatores.

\section{SUPOSTAS CAUSAS DA POBREZA}


A pobreza é um mal social que atinge toda a sociedade, pois a parcela pobre da população acaba por gerar gastos para o Estado, comprometendo dessa maneira a renda e outros setores daqueles que não são pobres.

Considerando que a pobreza nesse contexto é um fator econômico, é de grande importância que se entenda suas razões a partir de teóricos que se dedicaram ao estudo da pobreza e suas possíveis causas.

Dois grandes teóricos que se dedicaram ao estudo das teorias populacionais e seus decorrentes problemas, foram Thomas Malthus e Karl Marx. O primeiro afirmou em sua obra Ensaio sobre a população, que a população cresce em progressão geométrica e que a produção de alimentos cresce em uma progressão aritmética.

Para o economista inglês o crescimento populacional é uma ameaça para a humanidade, sendo a miséria e a fome males necessários para a sobrevivência da espécie humana, segundo Malthus (1798, p.246):

\footnotetext{
Afirmo que o poder de crescimento da população é indefinidamente maior do que o poder que tem a terra de produzir meios de subsistência para o homem. [...] Por aquela lei da nossa natureza que torna o alimento necessário para a vida humana, os efeitos desses dois poderes desiguais devem ser mantidos iguais. Isso implica em um obstáculo que atua de modo firme e constante sobre a população, a partir da dificuldade da subsistência.
}

No entanto, observa-se no Brasil que apesar de ter tido um crescimento populacional relevante, segundo Camargo e Martine (1984, p.1): "a dinâmica populacional brasileira, se destaca por um nível elevado de crescimento"; ainda assim houve uma redução considerável da pobreza, segundo Cattani $(2005$, p.77) : "Nos últimos anos observa-se a redução do número de famílias situadas abaixo da linha de pobreza."

Portanto a teoria de Malthus não pode ser puramente aplicada aos dias de hoje, pois tratar a pobreza como um mal necessário seria acomodarse a ela, e um país socialmente desenvolvido, independentemente de ter ou não um crescimento populacional positivo, é entre outras coisas, aquele que consegue reduzir as taxas de pobreza na sociedade.

O outro teórico estudioso da pobreza apresentado neste trabalho, é Marx, autor de O Capital, que afirma que a população e todos os seus problemas, tais como a miséria e a fome estão relacionados a interesses econômicos. Para ele, a pobreza é fruto do sistema econômico capitalista, das relações estabelecidas entre as classes sociais. Nesse sentido Freitas 
(2012, p.1) define a pobreza como resultado das relações entre as classes sociais:

\begin{abstract}
As mudanças ocorridas no decorrer do século XVIII, com a consolidação do modo de produção capitalista, acarretaram profundas alterações na relação do homem com a natureza. Marx (1996, p.113), discorrendo sobre a guerra travada pelo capital para arrancar o campesinato da terra e para submeter a atividade agrícola à lógica mercantil, denunciou a exploração dos recursos naturais da colônia, que propiciou o enriquecimento de uma parcela da burguesia e intensificou a destruição desses recursos, sobretudo nos países do hemisfério sul.
\end{abstract}

É possível observar que a pobreza como estabeleceu Marx é derivada das relações entre as classes sociais, o sistema capitalista por si gera desigualdades materiais que originam a pobreza, ou pelo menos colabora para sua existência na sociedade. Silva (2010, p.157) defende o mesmo posicionamento que Marx quanto ao Brasil:

No Brasil, a pobreza aprofundou-se como consequência de um desenvolvimento concentrador da riqueza socialmente produzida e dos espaços territoriais, representados pelos grandes latifúndios no meio rural, e pela especulação imobiliá- ria no meio urbano. Tem raízes na formação sóciohistórica e econômica da sociedade brasileira.

Mas entende-se sobretudo que a redução da pobreza é (e deve ser cada vez mais) buscada a fim de manter o sistema capitalista em vigor. É parte do propósito da Constituição Federal que estabelece no seu artigo $3^{\circ}$, inciso III:

Art. $3^{\circ}$ Constituem objetivos fundamentais da República Federativa do Brasil: [..] III - erradicar a pobreza e a marginalização e reduzir as desigualdades sociais e regionais.

Considerando que as causas estão nas relações estabelecidas entre os indivíduos, e que é previsão legal a erradicação da pobreza, é preciso trabalhar no sentido de conhecer as consequências desse fenômeno social para assim propor meios alternativos de possíveis soluções. 
É certo que as causas da criminalidade podem ser de origem econômica, social e cultural e não é a intenção desse trabalho simplificar a causa da criminalidade apenas à pobreza, porém é passível de análise a relação estreita que existe entre um fator e o outro.

Nas palavras de Juliana Pereira (2007, p.4):

Acreditamos que existem muitas causas para o crime, mas admitimos que a violência intrínseca ao capitalismo alimenta a criminalização, afinal, na lei do mercado vale a lei do mais forte, o que contribui para a "normalidade" com que a sociedade moderna aceita os atos atentórios à vida humana.

O que equivale a dizer que as relações capitalistas influenciam à sociedade ao consumo, à busca pelo lucro e ao mercado sem limites, o que gera crescimento econômico e desenvolvimento, no entanto ao mesmo tempo, gera a desvalorização da vida humana, pois aquilo que se expõe no mercado adquire preço, sofre objetivação, tal como a força de trabalho, a informação e a própria criminalização.

A pobreza conduz à falta de oportunidades, de estudo, emprego e vida social digna conforme prevê a Constituição Federal; ela limita a vida dos pobres e também das outras classes sociais, pois os seus derivados acabam por afetar a toda coletividade.

O menos favorecido tende a optar pelo crime, pois compensa mais que um trabalho normal, nas relações capitalistas o individual vale mais que o coletivo, o que colabora para a escolha pelo crime, e assim a banalização da vida humana pelo capital.

O crime não atinge apenas uma parcela da sociedade, mas ela completa. Não há como excluir da criminalidade os ricos, nem da forma ativa, nem da passiva. A criminalidade é um mal social que corrói a moral e o Direito, não é um bem dos pobres apenas, mas o que leva à pobreza, também conduz ao crime. Resolvendo as causas da pobreza, automaticamente muitas das causas da criminalidade também serão tratadas. Muitas, não todas.

Nesse sentido, Telles (2001, p. 26):

[...] o Estado cria a figura do necessitado, que faz da pobreza um estigma pela evidência do fracasso do indivíduo em lidar com os azares da vida e que transforma a ajuda numa espécie de celebração pública de inferioridade, já que o acesso do indivíduo prova que seus filhos estão subnutridos, que ele próprio é um incapacitado para a vida em sociedade e que a desgraça é grande o suficiente para merecer a ajuda estatal. 
O Estado conforme Telles e segundo previu Marx, mantém a pobreza pois é útil para o sistema capitalista. No entanto, se o olhar econômico assim o vê, é fato que o Direito tem outro posicionamento, o de combater e erradicar a pobreza. Por isso se encarrega de estudos e produção de normas que são dotadas de obrigações solidárias entre os indivíduos a fim de promover a equidade e assim, a justiça.

Percebe-se que a criminalidade está inclusa na pobreza. O Estado dessa forma precisa criar meios de coibir a pobreza e assim minorará os índices da criminalidade, ou seja, é necessário investir em cultura, educação e melhores condições de trabalho.

\section{DIREITOS SOCIAIS COMO MANIFESTAÇÃO DA JUSTIÇA RAWLSIANA}

Jonh Rawls, (1921-2002), filósofo político americano em sua obra Teoria da justiça (1971) trata sobre a questão da equidade, ele propõe um contrato social imaginário, ou um acordo social onde todos os indivíduos estariam em situação de equidade, para explicar o que é justiça, como explica Sandel (2011, p.179):

\footnotetext{
Rawls acredita que dois princípios de justiça poderiam emergir do contrato hipotético. O primeiro oferece as mesmas liberdades básicas para todos os cidadãos, como liberdade de expressão e religião. Esse princípio sobrepõe-se a considerações sobre utilidade social e bem-estar geral. O segundo princípio refere-se à equidade social e econômica. Embora não requeira uma distribuição igualitária de renda e riqueza, ele permite apenas as desigualdades sociais e econômicas que beneficiam os membros menos favorecidos de uma sociedade.
}

Com esse acordo hipotético, Rawls considera que a justiça seria alcançada, pois a equidade social estabeleceria que seriam distribuídos à sociedade direitos e deveres, rendimentos e oportunidades, ainda que inseridos em uma sociedade capitalista.

Nesse contexto a pobreza é tratada como privação de capacidades, pois a ausência de recursos materiais faz com que capacidades individuais deixem de ser aproveitadas, e cheguem ao seu estágio de aprimoramento e utilização. 
Os Direitos sociais previstos na Constituição Federal, demonstram de forma prática o desejo de erradicação da pobreza expresso no artigo $3^{\circ}$, inciso III do mesmo diploma legal. Conforme a Lei maior:

"Art. $6^{\circ}$ São direitos sociais a educação, a saúde, a alimentação, o trabalho, a moradia, o transporte, o lazer, a segurança, a previdência social, a proteção à maternidade e à infância, a assistência aos desamparados, na forma desta Constituição."

Os direitos sociais são indicados no preâmbulo da CRFB/88, destacando assim sua importância no ordenamento jurídico pátrio, seu relevante papel na construção da cidadania, na erradicação da pobreza, e enfraquecimento da criminalidade.

A relação entre os direitos sociais e a justiça rawlsniana se estabelece no fato dos direitos sociais serem um instrumento para estabelecer a equidade na sociedade, e conforme Rawls a equidade é o caminho para atingir a justiça.

Conforme Luiz Júnior (2011, p.4):

A justiça rawlsiana procura resolver o conflito pela distribuição de bens sociais entre as pessoas. Um primeiro ponto de superação deste conflito como pensado por Rawls é considerar a sociedade como um sistema equitativo de cooperação. Rawls considera também que as pessoas são seres racionais e razoáveis, isto é, que possuem interesses próprios de acordo com a concepção de bem que formulam para as suas vidas, mas que, ao mesmo tempo, dispõemse, em função do sentido de justiça que possuem, a ponderar umas com as outras sobre quais os justos termos de cooperação devem nortear o convívio social e a distribuição dos benefícios sociais.

Ao prover meios adequados através de políticas públicas para que os direitos sociais sejam manifestos na sociedade, a Constituição Federal ao mesmo tempo distribui benefícios sociais, que os pobres não poderiam alcançar por si.

Os direitos sociais são por si mesmos benefícios ou favores estatais que o Estado se obriga à devida prestação como forma de intervir na sociedade para a construção do bem comum.

Contudo, não pode a pobreza compreendida apenas no sentido material, ser o fim das políticas públicas, ou sua erradicação se reduziria a prover meios materiais de subsistência, e não é essa a intenção do legislador no artigo $6^{\circ}$ da CRFB/88. A real intenção do constituinte é a de prover 
meios que aumentem as oportunidades das pessoas se desenvolverem e o deixar a pobreza ser apenas uma consequência do crescimento pessoal.

Estabelecer a equidade em uma sociedade, conforme as ideias de Rawls é trabalhar as oportunidades sociais, a fim de que os indivíduos tenham condições justas de concorrerem no mercado capitalista. Vinícius Almeida (2014, p.41) confirma esse pensamento:

\begin{abstract}
"Não ocorre apenas que melhor educação básica e serviço de saúde elevem diretamente a qualidade de vida; esses dois fatores também aumentam o potencial de a pessoa auferir renda e assim livrar-se da pobreza medida pela renda. Quanto mais inclusivo for o alcance da educação básica e dos serviços de saúde, maior será a probabilidade de que mesmo os potencialmente pobres tenham chance muito maior de superar a penúria."
\end{abstract}

Há exemplos de que as ideias de equidade de Rawls funcionam na prática, não é necessário criar novas leis, ou novas metas governamentais para erradicar a pobreza e seus males da sociedade brasileira, basta investir em políticas públicas eficazes que assegurem o que já está disposto na Constituição Federal nos direitos sociais, pois esses direitos se atendidos podem minorar o índice da criminalidade, tendo em vista a pobreza ser uma das causas.

Como exemplo prático da aplicação das ideias rawlsinianas, o economista indiano Sen (2010, p. 124) ressalta:

\footnotetext{
"Muitas economias asiáticas- o primeiro o Japão, depois a Coreia do Sul, Taiwan, Hong Kong e Cingapura, e mais tarde a China pósreforma e a Tailândia, bem com outros países do Leste e Sudeste Asiático- lograram um êxito notável na difusão das oportunidades econômicas graças a uma base social que proporcionavam sustentação adequada, como altos níveis de alfabetização e educação básica, bons serviços gerais de saúde, reformas agrárias concluídas, etc."
}

A confiança nas instituições é tida como fundamental em Rawls, pois a sociedade deve confiar na eficiência de suas instituições para se portarem como determina a lei. No Brasil, os direitos sociais apesar de serem garantidos na Constituição Federal, não tem o alcance que deveriam, o que enfraquece a confiança social no Estado, e leva ao descrédito das leis que deveriam ser o referencial para as relações.

Os direitos sociais são dessa maneira importante ferramenta para o estabelecimento da equidade, e assim da justiça em uma visão rawlsiniana. Segundo Rawls (1981, p.31): 


\begin{abstract}
"a justiça como equidade - caracteriza a sociedade bem-ordenada como aquela na qual todos aceitem e saibam que os outros aceitam os mesmos princípios de justiça, e as instituições sociais básicas geralmente satisfazem, e geralmente se sabe que elas satisfazem, esses princípios."
\end{abstract}

Portanto, a partir dessa perspectiva a justiça será possível quando houver a busca pela equidade; a vantagem do ordenamento jurídico brasileiro é que os direitos sociais previstos na $\mathrm{CRFB} / 88$, são o caminho traçado pelo Estado para ele mesmo trilhar em busca da justiça.

Através da efetivação dos direitos sociais, as capacidades individuais terão a oportunidade de se desenvolver, atuando o Estado como o propulsor do desenvolvimento de sua população, erradicando a pobreza e consequentemente reduzindo a criminalidade.

\title{
$5 \quad$ CONCLUSÃO
}

Conforme o exposto, conclui-se que a pobreza certamente não é um fator determinante da criminalidade, mas é um ponto importante na análise das causas que levam ao mundo do crime.

A pobreza quando tratada como a limitação das capacidades individuais e não apenas como falta de recursos materiais, amplia o rol obrigacional do Estado de prover condições de desenvolvimento à população. Os direitos sociais previstos no artigo $6^{\circ}$, são previsões que se trabalhadas de forma eficaz podem erradicar a pobreza, contudo, o que se observa é falta de vontade política em produzir políticas públicas que atendam à demanda social.

As notícias nos veículos midiáticos demonstram a falta de segurança, precárias condições de atendimento no SUS (sistema único de saúde), educação básica deficiente na grande parte das escolas públicas e transporte público em situações de lotação; uma exposição da ineficiência do Estado em prover o que propôs na Constituição Federal.

Se a receita para uma sociedade justa é a equidade que se presta e propõe aos indivíduos, como dispõe John Rawls em sua obra "Uma teoria da Justiça", o Brasil tem essa receita em mãos, pois os direitos sociais são o instrumento do Estado para a construção de uma sociedade equânime, que oferece a oportunidade de seus indivíduos trabalharem suas diferenças por meios justos de acesso, garantidos pela lei. 
Os direitos sociais são nesse sentido uma manifestação da justiça rawlsniana, tendo em vista propor meios de a sociedade erradicar por si só a pobreza, pois garante condições dignas de vida e assim conduz ao desenvolvimento das capacidades individuais, o que traz vantagens coletivas, como crescimento econômico e desenvolvimento social, como maior exemplo, a diminuição da criminalidade.

Portanto é de grande valia que o Estado de dedique ao atendimento dos direitos sociais como previstos na Constituição Federal, a fim de que não sejam apenas normas frias dispostas em uma lei inacessível para os pobres, pelo contrário, que os direitos sociais sejam o elo entre os pobres e à lei. Que a pobreza e a criminalidade sejam motivo de empenho político para sua efetiva erradicação, mas não sejam o fim em si mesmas das políticas públicas, pois se atendidas às disposições constitucionais, serão tão somente uma consequência da melhoria da qualidade de vida das populações.

Que o Brasil siga o exemplo dos países que se dedicaram ao provimento das condições básicas de vida à sua população, e assim desfrute da equidade e da justiça a fim de eliminar a pobreza e a desigualdade social que atinge todo o povo.

\section{REFERÊNCIAS BIBLIOGRÁFICAS}

ALMEIDA, Vinícius Oliveira de. Desenvolvimento para o Progresso Humano. (in) COSTA, Eliane. SILVA, Germano. SANTOS, Nivaldo. Cidadania, Justiça e relações sociais contemporâneas. Goiânia: Gráfica e editora América, p. 35-51, 2014

CATTANI, Antônio David. Desiguladades socioeconômicas: conceitos e problemas de pesquisa. Disponível em: < http://www.scielo.br/pdf/soc/n18/n18a05.pdf >> Acesso em 11/11/2015

Constituição Federal de 1988. Disponível em: http://www.planalto.gov.br/ccivil_03/constituicao/ConstituicaoCompilado.htm Acesso em: 07/11/2015

FREITAS, R.C.M; NUNES, L. S.; NÉLSIS C. M. A crítica marxista ao desenvolvimento (in) sustentável. Disponível em: < http://www.scielo.br/pdf/rk/v15n1/a04v15n1> Acesso em: 09/11/2015.

MALTHUS, Thomas Robert. Ensaio sobre a população. Disponível em:

<http://pt.scribd.com/doc/55325109/1-Thomas-Robert-Malthus-Ensaio-sobre-a-populacao\#scribd > Acesso em: 09/11/2015.

RABELO JUNIOR, Luis Augusto. A justiça como equidade em Jonh Rawls.

Disponível em: <http://www.ambito-juridico.com.br/site/index.php?n_link=revista_artigos_leitura\&artigo_id=10755>. Acesso em 11/11/2015.

RAWLS, John. Uma Teoria da Justiça. Brasília: Universidade de Brasília, 1981. 
SANDEL, Michael J. Justiça, o que é fazer a coisa certa. Rio de Janeiro: Civilização brasileira, 2012.

SEN, Amartya. Desenvolvimento como liberdade. São Paulo: Companhia das Letras, 2010.

SILVA, Maria Ozanira da Silva e. Pobreza, desigualdade e políticas públicas: caracterizando e problematizando a realidade brasileira. Disponível em: < https://periodicos.ufsc.br/index.php/katalysis/article/viewFile/16523/17325> Acesso em: 11/11/2015. 